\title{
Relações entre padrões de consumo doméstico de energia e níveis de renda familiar: estudo de caso no 140 Bairro Nhaconjo, Cidade da Beira, Moçambique
}

\section{Manuel Tomás Manuel $^{1}$ e Alfiado Victorino ${ }^{2}$}

\author{
${ }^{1}$ Universidade Licungo. Faculdade de Ciências e Tecnologia. Curso de Física. \\ Extensão da Beira. Moçambique. E-mail: mtmanuel136@gmail.com. \\ ${ }^{2}$ Universidade Licungo. Faculdade de Ciências e Tecnologia. Extensão da Beira. \\ Moçambique.
}

Resumo. Este artigo analisa o impacto da renda sobre os padrões de consumo doméstico de energia no 14ํㅡ Bairro urbano denominado Nhaconjo, localizado no Município da Cidade da Beira, no centro de Moçambique. Com base no questionário, as famílias inqueridas foram classificadas em nove grupos de níveis de renda. Os resultados confirmam a hipótese de que com o aumento da renda o consumo doméstico de energia tende a aumentar, mas a um ritmo desigual. Também, foi possível verificar que quanto menor for a renda há mais participação de combustíveis que se encontra na base inferior da "escada de energia", no caso da lenha e serradura.

Palavras-chave: Energia; Consumo doméstico de energia; Renda familiar.

Abstract. Relationship between household consumption standards and family income levels: Case study in the 14th Nhaconjo Neighborhood, Beira City, Mozambique. This paper analyses the impact of income on household energy consumption patterns in the 14th Nhaconjo Urban Neighborhood, located in the City of Beira Municipality in central Mozambique. Based on the questionnaire, the surveyed families were classified into nine income level groups. The results confirm the hypothesis that with rising incomes, domestic energy consumption tends to increase, but at an uneven pace. Also, it was possible to verify that the lower the income, the more fuel participation is found at the bottom of the "energy ladder", in the case of firewood and sawdust.

Keywords: Energy; Domestic consumption of energy; Family income.

Resumen. Relación entre normas de consumo del hogar y niveles de ingresos familiares: Estudio de caso en el 14º Barrio de Nhaconjo, Ciudad de Beira, Moçambique. Este artículo

Recebido

$22 / 03 / 2020$

Aceito

$27 / 07 / 2020$

Disponível on line $30 / 07 / 2020$

Publicado

$31 / 08 / 2020$

Acesso aberto

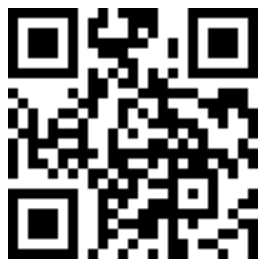

ORCID

(D) 0000-0001-5101-6326 Manuel Tomás Manuel

(D) 0000-0003-3134-3607 Alfiado Victorino

ISSN 2359-1412/RBGAS-2020-0045/2020/7/16/11/619

Rev. Bras. Gest. Amb. Sustent.

http://revista.ecogestaobrasil.net 
analiza el impacto de los ingresos en los patrones de consumo de energía de los hogares en el 14ํㅡㅁ Barrio Urbano de Nhaconjo, ubicado en la ciudad de Beira, en el centro de Mozambique. Según el cuestionario, las familias encuestadas se clasificaron en nueve grupos de nivel de ingresos. Los resultados confirman la hipótesis de que con el aumento de los ingresos, el consumo interno de energía tiende a aumentar, pero a un ritmo desigual. Además, fue posible verificar que cuanto menor es el ingreso, mayor participación de combustible se encuentra en la parte inferior de la "escalera de energía", en el caso de la leña y el aserrín.

Palabras clave: Energía; Consumo interno de energía; Ingresos familiares.

\section{Introdução}

Energia é indiscutivelmente um dos maiores desafios que o mundo enfrenta hoje, tocando todos os aspectos de nossas vidas. 0 acesso à energia, é a chave para o sucesso de qualquer iniciativa de desenvolvimento e é importante entender os factores que determinam o seu uso. 0 consumo de energia é uma prática que busca a satisfação dos indivíduos, por meio de gastos na compra de combustíveis, com a finalidade de suprir as suas necessidades e desejos (Silva et al., 2018). No sector residencial o uso de energia satisfaz vários serviços energéticos muito associados com qualidade de vida das pessoas, desde a iluminação, refrigeração, aquecimento de água, cozinha, entretenimento e serviços gerais.

A distribuição do consumo doméstico de energia está relacionada à vários factores socioeconómicos, mas é influenciada, principalmente, pelas modificações que ocorrem na sociedade, tais como: as características gerais de cada família, como o número de pessoas que as constituem, a sua composição etária (presença de pessoas dependentes e activas economicamente), o perfil do seu "chefe" (sexo, nível de escolaridade, ocupação), riqueza, preço de outros bens, propaganda, hábitos, entre outras características (Carvalho e Alves, 2010; Silva, 2013).

Dos vários factores arrolados acima este artigo destaca a renda mensal das famílias, medida em salários mínimos, auferidos e declarados pela família. Visto que, a renda é um dos principais factores que influencia o consumo de energia nas famílias, pois o indivíduo tende a adequar, pelo menos no longo prazo, seus gastos à sua restrição orçamentária. Por esta razão, uma atenção considerável tem sido colocada sobre a estimativa da relação entre o consumo de energia e renda familiar.

Para alguns autores, como Tafner e Ferreira (2005), Neri (2011), Uchôa et al. (2013), a renda é um indicador de posição económica e social. Em outros estudos, como Guerra et al. (2006), SAE (2012), Uchôa et al. (2013) e Manuel e Victorino (2020a, b), a renda é utilizada por ser uma variável de fácil compreensão, mensuração e também por ser aquela que melhor traduz uma sociedade de mercado. Neste trabalho considerou-se o pensamento de que a economia é o factor mais importante de decisão para as famílias.

Nesta base, diversos autores, em diferentes países ao longo de vários períodos de tempo, usando diferentes metodologias, como Cohen (2002), Cohen et al. (2005), Rocha e Dias (2007), Carvalho e Alves (2010), Arancibia (2012), Uchôa et al. (2013), Weiss (2015), Silva et al. (2018), no Brasil, Arthur (2012), Atanassov et al. (2012), em Moçambique, Drukman e Jackson (2008), no Reino Unido, Deloitte (2017), Ateba et al. (2018), na África do Sul, Crompton e Wu (2005), na China, Hasan e Mozumder (2017), em Bangladesh, e Jamasb e Meier, 2010, na Grã-Bretanha, realizaram análises sobre a relação entre padrões 
de consumo doméstico de energia e níveis de renda. Nestas análises, observa-se uma relação directamente proporcional entre o consumo de energia e o crescimento da renda. Isto é, maior será o consumo de energia quanto maior for o nível de renda observado, tanto em termos de quantidade total de energia consumida, quanto em relação à qualidade do serviço energético demandado. Este artigo pretende contribuir no debate aberto sobre o assunto inscrevendo nele a realidade referente ao Município da Beira, mais concretamente no $14^{\circ}$ Bairro Nhaconjo.

Segundo Uchôa et al. (2013), esse tipo de pesquisa assume grande importância na medida em que nem todos os países encontram-se no mesmo nível de desenvolvimento. Mas isso não significa que os países menos desenvolvidos, por terem menores níveis de renda, também não apresentem elevadas taxas de consumo de energia. Então é preciso conhecer melhor quais os padrões de consumo destas sociedades e em que bases se apoiam.

A evidência empírica de estudos anteriores sobre o assunto mostra claramente que a relação entre o consumo de energia e crescimento económico é significativa. Pois, os gastos de energia tendem a variar na medida que a renda aumenta. Tais derivações fizeram com que Keynes formulasse a teoria de consumo em 1936, vulgarmente conhecido por Teoria de Consumo Keynesiana; que resumidamente, afirma que: "os indivíduos tendem, como regra e na média, a aumentar seu consumo quando sua renda aumenta, mas não na mesma proporção do aumento da renda" (Keynes, 1992). Para Keynes, o montante que a comunidade gasta em consumo depende, evidentemente: (i) em parte, do montante de sua renda; (ii) em parte, de outras circunstâncias objectivas que o acompanham; e (iii), em parte, das necessidades subjectivas, propensões psicológicas e hábitos dos indivíduos que a compõem, bem como dos princípios que governam a distribuição da renda entre eles [...] (Keynes 1992; Rocha e Dias, 2007).

Também, levaram a Hosier e Dowd (1987), no Zimbabwe, a formular o conceito de "escada de energia", que estabelece uma relação directa entre renda e o tipo de combustível, afirmando que as famílias farão a transição a partir de biomassa a fontes modernas como consequência de aumentos na sua renda. Convencionalmente, para Arthur \& Bucini (2010), a escada de energia coloca as fontes mais baratas (biomassa) na parte inferior (usada pelas famílias de baixa renda) e as mais caras no topo (GLP e electricidade), também chamado de "combustíveis modernos" (Kebede et al., 2002; Howells et al., 2005).

0 objectivo do presente artigo é analisar a relação dos padrões de consumo doméstico de energia em função dos níveis de renda mensal nas famílias que residem no 140 Bairro Nhaconjo, localizado no Município da Cidade da Beira, no centro de Moçambique, buscando responder duas questões: a primeira é, o quanto de uma renda familiar é dedicada à energia e, a segunda é, como a parcela de gastos de energia é distribuída entre os diferentes combustíveis. Entretanto, duas hipóteses norteiam essa pesquisa, a primeira traz á frente o debate de que, com o aumento da renda, o consumo e a qualidade dos suprimentos energéticos deve aumentar, e a segunda é de que grupos de maior renda consomem mais energia do que grupos de renda baixa.

Como o foco deste artigo são os níveis de renda e as diferenças dos gastos na compra de combustíveis para fins domésticos, algumas análises são relevantes e importante para o entendimento da questão da pobreza energética, definido, por Jamasb e Meier (2010) como os gastos de energia abaixo de $10 \%$ da renda familiar, provocada pelos preços de energia, baixa eficiência energética das habitações e o nível de renda.

Como melhor forma de compreender o objectivo proposto, o artigo é constituído por quatro seções, além desta nota introdutória. A próxima seção apresenta os materiais e métodos. A terceira seção traz a apresentação, analise e discussão dos resultados, comentados com destaque para o perfil dos inqueridos e padrões de consumo doméstico 
de energia em função da renda familiar. A última seção apresenta as conclusões e recomendações para trabalhos futuros.

\section{Materiais e métodos}

A área de estudo foi o Bairro Nhaconjo, localizado no Município da Cidade da Beira, no Centro de Moçambique, constituído de 7.805 agregados familiares (INE, 2017), na qual extraiu-se uma amostra de 49 residências de forma aleatória, considerando o factor de correcção para uma população finita e seguindo os critérios propostos por Deus (2014) e Gil (2008). 0 bairro localiza-se ao longo da Estrada Nacional no 6 (EN6) e compõe o Posto Administrativo de Inhamizua ( $n^{\circ}$ 3), limitado a norte pelo Bairro Vila Massane e Mungassa, a Sul pelo Bairro Alto da Manga, a Este pelo Bairro Ndunda e a Oeste pelo Bairro de Inhamizua.

A colecta de dados foi feita em duas fases, sendo a primeira relativa à aplicação de um questionário por entrevista com a pessoa de referência, a pessoa responsável "pelas despesas de habitação (IBGE, 1997; Dominik, 2010; Dominik et al., 2012), ou aquela indicada pelos membros da família para obtenção de dados socioeconómicos; e na segunda fase a determinação do consumo médio dos combustíveis usados nas residências seleccionadas.

O questionário aplicado compôs-se de três partes: 1) caracterização dos inqueridos e suas residências; 2) padrões de consumo doméstico de energia e 3) renda mensal das famílias. 0 valor da renda familiar foi estimado tendo como base o salário mínimo aprovado recentemente pelo Governo Moçambicano (neste 2019 o aumento salarial foi de MT 4.467,75). Considerou-se o total da renda familiar, incluindo o salário, rendimentos de negócios, remessa de parentes e outros rendimentos declarados pelos inqueridos. Para tal, agrupou-se as famílias em nove níveis de renda.

A caracterização dos combustíveis usados pelas famílias foi feita considerando algumas propriedades físicas (massa e poderes caloríficos), ilustrados na Tabela 1.

Tabela 1. Caracterização dos combustíveis.

\begin{tabular}{|l|c|c|c|}
\hline \multicolumn{1}{|c|}{ Fonte/Combustível } & Unidade & Massa (m) por mês & Poder calorífico (Kcal) \\
\hline Electricidade & $\mathrm{kWh}$ & 60,5 & 860 \\
\hline Carvão vegetal & $\mathrm{kg}$ & 57,4 & 5.000 \\
\hline GLP & $\mathrm{kg}$ & 11,0 & 11.500 \\
\hline Lenha & $\mathrm{kg}$ & 23,0 & 2.900 \\
\hline Serradura & $\mathrm{kg}$ & 7,9 & 3.330 (lenha mista) \\
\hline Querosene & $\mathrm{L}$ & 0,75 & 10.000 \\
\hline Vela $\left(^{*}\right)$ & $\mathrm{kg}$ & 1,105 & 10.000 \\
\hline Pilha $(* *)$ & $\mathrm{V}$ & 3,0 & --- \\
\hline
\end{tabular}

Fonte; GASMIG (2019).

$\left({ }^{*}\right) 0$ poder calorífico dos derivados de petróleo (querosene, parafina) variam de $10.000 \mathrm{kcal} / \mathrm{kg}$. A vela é feita normalmente de parafina, que é um derivado de petróleo, por isso considerou-se o poder calorifico do petróleo.

${ }^{* *}$ ) Considerou-se a seguinte relação: $1 \mathrm{~V}=1,6 \times 10^{-19} \mathrm{~J}$

A quantidade de energia na forma de calor (QC) foi expressa pela Equação 1 (Vale et al., 2003) e depois considerou-se a relação $1 \mathrm{kcal}=4,18 \mathrm{~kJ}$ :

$$
\mathrm{Q}_{\mathrm{C}}=\mathrm{m} * \mathrm{P}_{\mathrm{C}}
$$


Onde:

Qc: Quantidade de calor/Energia (J, e suas derivações, como KJ: kilojoule; MJ: megajoule); m: massa do combustível (kg); e $\mathrm{P}_{\mathrm{C}}$ : Poder calorífico líquido (kcal).

\section{Resultados e discussão}

\section{Perfil dos inqueridos e suas residências}

Dentro das famílias amostradas, a maior parte é composta por agregados familiares chefiados por homens (86\%), e um número considerável (14\%) é chefiada por mulheres (Tabela 2), possuem entre 31 a 40 anos. As suas rendas mensais sustentam 5 a 6 pessoas, sendo que 43\% são crianças (até 18 anos de idade) e 57\% são adultos. Destes, a maior parte possui o ensino primário (29\%), ensino secundário (28\%) e 19\% ensino superior.

Tabela 2. Chefes de agregados familiares.

\begin{tabular}{|l|c|c|}
\hline Chefes de agregados familiares & $\mathbf{N} \times$ & \% \\
\hline Homens & 42 & 86 \\
\hline Mulheres & 7 & 14 \\
\hline Total & 49 & 100 \\
\hline
\end{tabular}

Quanto à profissão ou ocupação laboral que dá um rendimento ao chefe da família ou representante, para que possa sustentar o seu agregado familiar no final do mês, os resultados obtidos sugerem uma diversidade profissional (Figura 1).

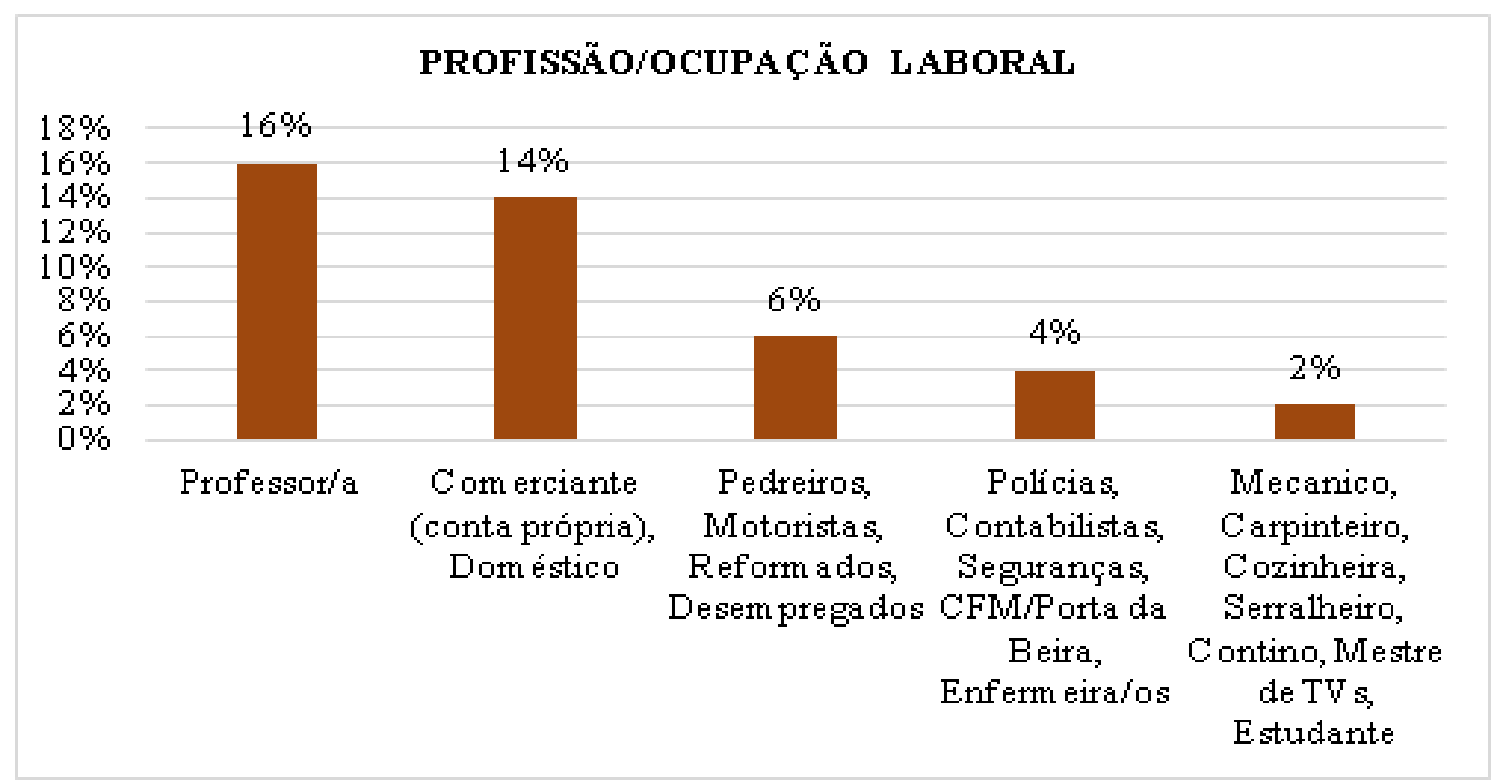

Figura 1. Percentagem dos inqueridos em função da profissão ou ocupação laboral. 
A maioria das famílias recebem um salário através do emprego (16\%). A segunda actividade mais indicada para a geração de renda é o auto-emprego, praticado por $14 \%$ dos inqueridos.

Quanto à habitação, os inqueridos caracterizam-se por possuir casas de alvenaria de blocos de cimento (90\%), cobertos na sua maioria de chapa de zinco (51\%) e lusalite (43\%). Com relação a aquisição $67 \%$ dos inqueridos têm a casa própria/construída e 18\% têm a casa alugada.

\section{Padrões de consumo doméstico de energia}

Os combustíveis mais preferidos e consumidos pelos inqueridos é a electricidade e o carvão vegetal (Figura 2). 0 consumo de electricidade chega a $100 \%$ das residências, equivalente a $217 \mathrm{MJ} /$ mês e $2.609 \mathrm{MJ} /$ ano com um consumo per capita estimado em $444,5 \mathrm{kWh}$, sendo utilizada para a iluminação e para funcionamento de bens domésticos.

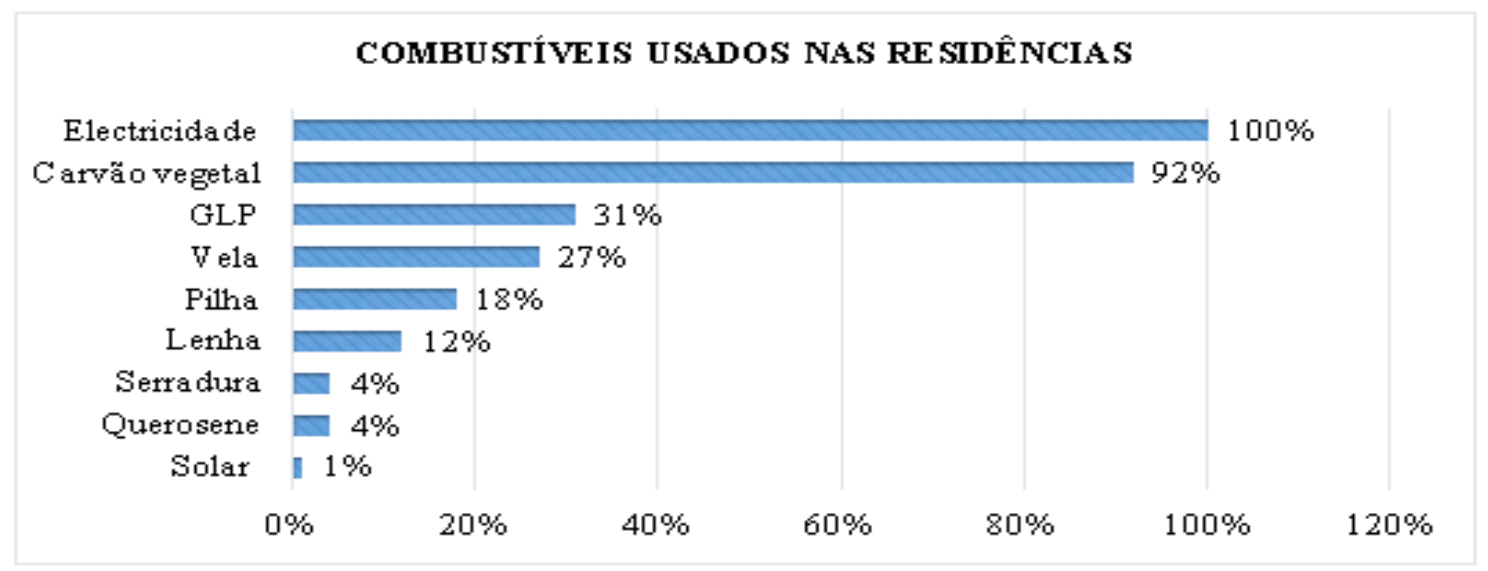

Figura 2. Percentagem das residências em função do combustível doméstico utilizado.

A confecção de alimentos é feita na sua maioria com base no carvão vegetal (92\%), equivalente a $1.199 \mathrm{MJ} /$ mês e $14.395 \mathrm{MJ} /$ ano com um consumo per capita estimado em $421,8 \mathrm{~kg}$, com auxílio de fogão a carvão (78\%), sendo que $13 \%$ das residências possuem fogão a GLP, $7 \%$ fogão eléctrico e apenas $1 \%$ possuem fogão a lenha e a serradura (cujo o consumo da lenha ronda nos $278 \mathrm{MJ} /$ mês a $3.345 \mathrm{MJ} /$ ano e da serradura nos $109 \mathrm{MJ} / \mathrm{mês}$ a $1.319 \mathrm{MJ} / \mathrm{ano}$ com um consumo per capita estimado em 34,3 kg e 3,9 kg, respectivamente).

Independentemente do nível renda analisado todos famílias inqueridas usam lâmpadas eléctricas para a finalidade de iluminação. A querosene (com uma média de consumo de $31 \mathrm{MJ} /$ mês a $376 \mathrm{MJ} /$ ano e um consumo per capita estimado em 0,37 L), vela (46 MJ/mês a $554 \mathrm{MJ} /$ ano e um consumo per capita estimado em 4 velas) e a pilha

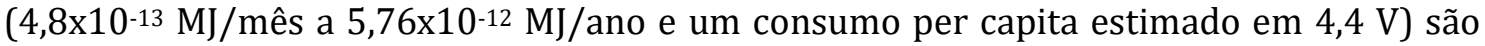
usados como segunda alternativa, em casos de corte de fornecimento de electricidade.

Os combustíveis até aqui mencionados são adquiridos em muitos casos por via da compra (90\%) no mercado ou na rua, efectuada na maioria das vezes por mulheres e crianças. Esta actividade (de adquirir e recolha) dos combustíveis consome árduo e tempo, com graves implicações directas a saúde, tais como, problemas na coluna vertebral pelo excesso de peso, redução de tempo de estudo das crianças ou redução da frequência na escola, principalmente em caso de escassez dos combustíveis. 
Ao considerar o número de refeições preparadas por dia, os inqueridos relatam cozinhar três refeições por dia (pequeno almoço, almoço e jantar); cozinhando dentro de casa ou na varanda. Entretanto, foi também, constatado que ferver a água é uma tarefa diária entre os inqueridos para diversos fins, como fazer chá, banho, bem como o tratamento (desinfecção) de água para beber. Para tal, diferentes tipos de combustível são usados para ferver a água, a electricidade é de longe a fonte de energia mais comum para este fim (35\%), sob a forma quer de fogões eléctricos ou chaleiras eléctricas, seguida de carvão vegetal (29\%).

Os resultados encontrados nessa secção, corroboram com os do IOF (2015), do Serviço Nacional de Estatística de Moçambique (INE), que afirma existir para a província de Sofala maior número de agregados familiares chefiados por homens, com idade mínima de 24 anos e máxima de 62 anos, cuja a média de pessoas por residência é de 6 pessoas e a nível nacional é de 5 pessoas. Também, faz-se menção que, na área urbana, aproximadamente $70 \%$ de agregados familiares tem a energia eléctrica como a principal fonte de iluminação e os restantes 30\% utilizam outras fontes de iluminação (querosene, velas e lanternas) como segunda alternativa.

Resultados semelhantes, também, foram encontrados por Atanassov et al. (2012), no seu estudo sobre análise da dinâmica de uso de energia dentro das grandes áreas urbana de Moçambique (Maputo, Beira e Nampula), no qual faz referência que para a Cidade da Beira as famílias dependem de múltiplas fontes de combustível para satisfazer as suas necessidades. 0 carvão vegetal (64\%) é o principal combustível usado para cozinha, sendo assim o fogão a carvão é o mais predominante (85\%), com maior parte deles cozinhando dentro da casa (principalmente na estacão chuvosa). 0 consumo médio diário de electricidade foi de 1,65 kWh/dia/residência; $2,495 \mathrm{~kg} /$ dia de carvão vegetal, os utilizadores de lenha $2,9 \mathrm{~kg} /$ dia; aqueles que cozinham exclusivamente a GPL consumiam $367 \mathrm{~g}$ de GLP por dia.

\section{familiar \\ Análise dos padrões de consumo doméstico de energia em função da renda \\ Com base nas respostas dos inqueridos, nove níveis de rendimento mensal são classificados, conforme ilustrado na Tabela 2.}

Tabela 3. Níveis de renda mensal dos inqueridos.

\begin{tabular}{|c|c|c|c|c|}
\hline $\begin{array}{c}\text { Nível de } \\
\text { renda/mês }\end{array}$ & Designação & $\begin{array}{c}\text { Valor Monetário } \\
\text { (MT*) }\end{array}$ & $\begin{array}{c}\text { No de agregados } \\
\text { familiares }\end{array}$ & Percentagem \\
\hline $\mathrm{A}$ & $\begin{array}{c}\text { Abaixo de 1 salário } \\
\text { mínimo }\end{array}$ & $2.233,90$ & 10 & $20 \%$ \\
\hline $\mathrm{B}$ & 1 salário mínimo & $4.467,75$ & 6 & $12 \%$ \\
\hline $\mathrm{C}$ & $\begin{array}{c}\text { Entre 1 a 2 salários } \\
\text { mínimo }\end{array}$ & $6.701,63$ & 3 & $6 \%$ \\
\hline $\mathrm{D}$ & 2 salários mínimo & $8.935,50$ & 13 & $27 \%$ \\
\hline $\mathrm{E}$ & 3 salários mínimo & $13.403,25$ & 12 & $24,5 \%$ \\
\hline $\mathrm{F}$ & 4 salários mínimo & $17.871,00$ & 1 & $2 \%$ \\
\hline $\mathrm{G}$ & 5 salários mínimo & $22.338,75$ & 2 & $2 \%$ \\
\hline $\mathrm{H}$ & 6 salários mínimo & $26.806,50$ & 1 & $2 \%$ \\
\hline $\mathrm{I}$ & 8 salários mínimo & $35.742,00$ & 1 & $100 \%$ \\
\hline Total & 9 & -- & 49 & \\
\hline
\end{tabular}

*MT = Metical. A cotação do metical, em 14 de novembro de 2019, foi 1 USD (US\$) = 62,29 MT e $1 \mathrm{BRL}(\mathrm{R} \$)=14,91 \mathrm{MT}$. 
De acordo com a tabela acima, a maioria das famílias se enquadra no nível de renda D (27\%), seguida de nível E $(24,5 \%)$ e A (20\%), as restantes famílias estão abaixo dessas percentagens.

Conforme proposto pelo trabalho, a relação da estimativa dos gastos na compra dos combustíveis em função dos níveis de renda mensal dos inqueridos é ilustrado na Tabela 4.

Tabela 4. Consumo doméstico de energia em função dos níveis de renda mensal.

\begin{tabular}{|c|c|c|c|c|c|c|c|c|c|c|}
\hline \multirow[b]{2}{*}{$\begin{array}{c}\text { Participação } \\
\text { das Fontes/ } \\
\text { combustíveis }\end{array}$} & \multicolumn{9}{|c|}{ Renda Familiar por salário mínimo $(4.467,75$ Meticais $)$} & \multirow{11}{*}{$\begin{array}{c}\text { Gasto mensal } \\
\text { na compra } \\
\text { dos } \\
\text { combustíveis } \\
\text { (Em Meticais) }\end{array}$} \\
\hline & $\begin{array}{l}\text { A: } \\
<1\end{array}$ & $\begin{array}{l}\text { B: } \\
=1\end{array}$ & $\begin{array}{c}\text { C: } \\
\text { Entre } \\
1-2\end{array}$ & $\begin{array}{l}\text { D: } \\
=2\end{array}$ & $\begin{array}{c}\text { E: } \\
=3\end{array}$ & $\begin{array}{l}F: \\
=4\end{array}$ & $\begin{array}{l}\text { G: } \\
=5\end{array}$ & $\begin{array}{l}H: \\
=6\end{array}$ & $\begin{array}{l}\text { I: } \\
=8\end{array}$ & \\
\hline Electricidade & 179,3 & 243,8 & 600,0 & 562,5 & 941,6 & 1250 & 1500 & 2500 & 1750 & \\
\hline Carvão & 181,3 & 554,2 & 333,3 & 531,3 & 527,9 & 230 & 575 & 230 & 750 & \\
\hline GLP & -- & -- & -- & 673 & 716,7 & 750 & 695 & 750 & 916 & \\
\hline Lenha & $\begin{array}{c}100 \mathrm{e} \\
\text { Col. }\end{array}$ & $\begin{array}{l}50 \mathrm{e} \\
\text { Col. }\end{array}$ & -- & -- & -- & -- & -- & -- & -- & \\
\hline Serradura & Col. & Col. & -- & -- & -- & -- & -- & -- & -- & \\
\hline Vela & 35 & 45 & 30 & 55 & 45 & 55 & 45 & 50 & 45 & \\
\hline Pilha & 45 & 30 & 52,5 & -- & & 50 & -- & -- & -- & \\
\hline Querosene & 25 & -- & -- & -- & -- & -- & -- & -- & -- & \\
\hline Gasto total & 595,3 & 923 & 1016 & 1822 & 2231 & 2335 & 2815 & 3530 & 3461 & \\
\hline
\end{tabular}

Col. $=$ Coleta.

A Tabela 4 mostra que, em relação ao consumo dos combustíveis, quase todos agregados familiares, independentemente do nível de renda usam a electricidade, o carvão vegetal e a vela. No entanto, o gasto e as quantidades de combustíveis adquiridos são diferentes para cada nível, principalmente para a electricidade que mostra ser bastante sensível à renda, aumentando na mesma proporção esta.

Os resultados confirmam que, independentemente do nível de renda, todos os inqueridos estão ligados à rede eléctrica, através de um sistema pré-pago (vulgo "Credelec"). A Tabela 4, mostra um aumento substancial das despesas de electricidade nas famílias de maior nível de renda. Esta variação da quantidade de electricidade comprada (consumida) em função da renda é influenciada muitas vezes pela posse de aparelhos eléctricos, pois, as famílias com renda maior tendem a adquirir mais electrodomésticos, razão pela qual o seu consumo tende a crescer na medida que a renda mensal da família aumenta. Deloitte (2017), no seu estudo sobre consumo de electricidade e os preços na África do Sul, mostrou que um aumento de $1 \%$ em renda ou PIB seria tipicamente associado a um aumento no consumo de electricidade de $0,8 \%$ a $1,1 \%$.

Observa-se, também que, quando o rendimento é baixo, a lenha e a serradura domina no portefólio da energia utilizada para cozinhar, com um pouco de serradura. Isto deve-se ao facto de a lenha e a serradura estarem disponíveis com facilidade para colecta manual, e sem ónus para o usuário, estes são principais combustíveis (incluindo a querosene) para muitas famílias de baixa renda. Este resultado confirma a hipótese de "escada de energia" e a hipótese de que estes combustíveis são mais utilizados pelas famílias de baixa renda, pois, na medida em que a renda aumenta, esses combustíveis deixam de fazer parte, isto é, têm uma relação directa com baixos índices de desenvolvimento económico. Esta tendência é confirmada por vários estudos realizados 
sobre o tema (Moraes et al., 2008; Carvalho e Silva, 2012; Coelho et al., 2018), só para citar alguns.

O carvão vegetal, está presente em todos níveis de renda, como principal combustível para confecção dos alimentos e o seu consumo cresce na medida em que a renda cresce, mas não na mesma proporção, isto é, apresentando uma tendência de comportamento pouco elástico em relação ao nível de renda. Este resultado corrobora com a Teoria de consumo keynesiana ao afirmar que, o consumo segue uma tendência de crescimento da renda, mas a um ritmo desigual.

A quantidade de GLP consumida pelas famílias analisadas mostra-se fortemente relacionado com o nível de rendimento das famílias, principalmente para aquelas com altos níveis de renda. No entanto, quando a renda da família aumenta, sua parcela do consumo de GLP sobe. Mas, segundo Yanagisawa (2012), a quantidade comprada diminui em linha com o aumento da renda, isto é, a quantidade comprada de GLP para coacção permanece mais ou menos no mesmo nível, independentemente do nível de renda.

A quantidade de velas e pilhas comprada permanece mais ou menos no mesmo nível, independentemente do nível de renda, sendo assim, não mostraram grandes alterações, pois, são usados em caso de interrupções de electricidade, fazendo-se presente nas famílias quando há necessidade.

De acordo com a Figura 3, pode se verificar que as faixas de renda mais baixas coincidem com o consumo de energia mais baixo. A seguir surgem outras faixas de renda mais altas que vão se alternando e crescendo, alterando o consumo de energia para o mais alto. Dando evidências claras de que, os consumidores de energia mais elevados estão nos níveis mais altos de renda, isto é, 0 aumento da renda familiar exerce uma influência positiva robusta sobre o consumo (mas não na mesma proporção) na escolha dos combustíveis.

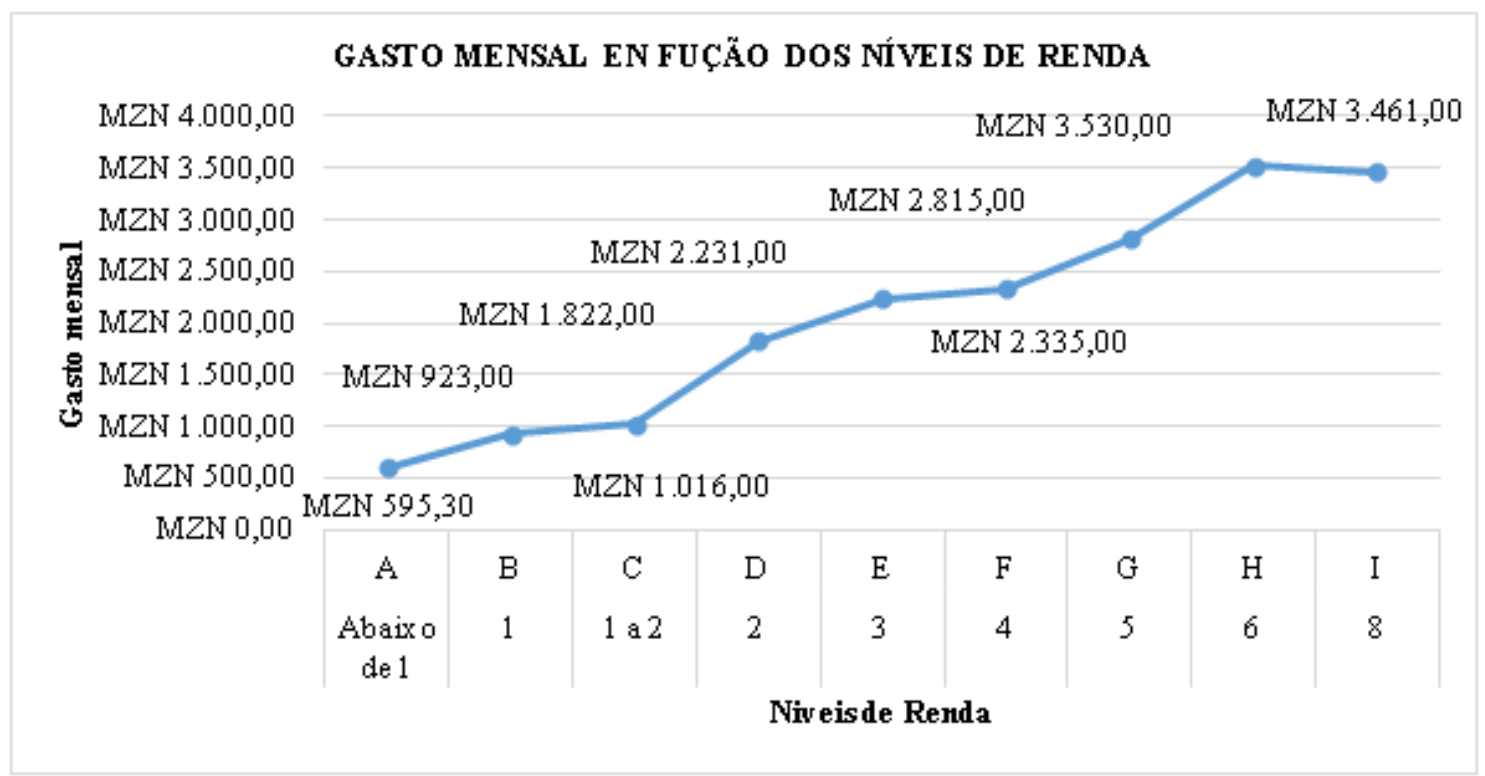

Figura 3. Consumo de energia em função dos gastos com os níveis de renda mensal dos inqueridos.

Estes resultados confirmam o consenso das duas teorias anteriormente mencionadas, a teoria escada de energia, que implica que as pessoas só vão subir a escada 
de energia quando há um aumento na sua renda e a Teoria de Consumo Keynesiana, mas não na mesma proporção do aumento da renda.

\section{Conclusões}

De acordo com os objectivos definidos e a metodologia adoptada, o estudo feito neste artigo mostra que:

$>$ A concentração dos inqueridos está nos níveis de renda D: com dois salários mínimos (27\%), seguida de nível E: 3 salários mínimos (24,5\%) e nível A: abaixo de 1 salário mínimo (20\%).

$>0$ dinheiro médio gasto para a compra de combustível por família é em grande parte com base no tipo de combustível comprado, bem como as quantidades compradas de uma só vez.

> As famílias do nível A gastam em média para a compra dos combustíveis 595,3 MT (MZN) por mês, as do nível B $932 \mathrm{MT} / \mathrm{mês}$, do nível C $1.016 \mathrm{MT} / \mathrm{mês}$, do nível D $1.822 \mathrm{MT} / \mathrm{mês}$, do nível E $2.231 \mathrm{MT} / \mathrm{mês}$, do nível F $2.335 \mathrm{MT} / \mathrm{mês}$, do nível G 2.815 MT/mês, do nível H 3.530 MT/mês e do nível I 3.461 MT/mês.

> 0 gasto médio mensal com electricidade é 1.058,6 MT/mês; com o GLP as famílias gastam em média $750 \mathrm{MT} / \mathrm{mês;} 125 \mathrm{MT} /$ mês na compra de lenha; $45 \mathrm{MT} /$ mês na compra de vela; $44 \mathrm{MT} /$ mês na compra de pilha e $25 \mathrm{MT} /$ mês na compra de querosene. De referir que a serradura é adquirida por via da colecta.

$>$ No que diz respeito às despesas de carvão vegetal, $70 \%$ dos usuários de carvão compram esse combustível em saco (+ $57 \mathrm{~kg} / \mathrm{mês}$ ). Fazendo isso, eles gastam em média $435 \mathrm{MT} / \mathrm{mês}$ em carvão. Deve-se notar, porém, que os agregados familiares que são dependentes apenas em carvão vegetal para todas as necessidades de cozinha, gastam em média um valor acima do mencionado para o seu combustível se comprado por saco assim como por plastiquinho ou molho.

> Como observado em muitos estudos realizados em países em desenvolvimento ou não, as mulheres e crianças são as responsáveis pela obtenção dos combustíveis.

$>$ O consumo de um ou outro combustível (lenha, serradura, GLP, querosene, electricidade) nos diferentes usos finais varia entre os níveis de renda, ou seja, está associado ao poder aquisitivo. Principalmente a electricidade é geralmente mais sensíveis à renda do que ao preço e que a renda é, portanto, o motorista da demanda mais dominante.

$>$ Como o nível de renda aumenta, a demanda por formas modernas de energia vai aumentar simultaneamente. Carvão e gás para cozinhar e electricidade para a iluminação, seguindo esta tendência geral. Sendo assim, a participação das famílias que utilizam lenha para cozinhar e querosene para iluminação diminui à medida que os níveis de renda aumentam, isto é, quanto menor for a renda há mais participação de combustíveis que se encontra na base ou abaixo da "escada de energia", no caso da lenha e serradura.

No entanto, o presente estudo revelou de forma empírica que os padrões de consumo doméstico de energia variam de uma forma razoável de acordo com a renda. À primeira vista, a escada de energia parece segurar. Ou seja, os agregados familiares com níveis de renda mais altos mostram uma maior tendência para utilizar suprimentos de energia de maior qualidade.

Além disso, esta análise mostrou ainda que há muitos desenvolvimentos possíveis para dar prosseguimento a este trabalho inicial. De facto, como a função básica deste trabalho era corroborar algumas hipóteses e teorias aventadas ao longo deste artigo, não se esgotaram todas as possibilidades de uso da base de dados construída acerca das 
relações entre energia e níveis de renda. Nesse sentido, ressalta-se a importância de realizar mais pesquisas que aprofundem este tema, tomando por base a estrutura dos padrões de consumo energético pesquisada, como por exemplo, monitorar os gastos de energia de tipos específicos de famílias ao longo de outras dimensões, como aposentados, mães monoparentais, ou aqueles em diferentes tipos de benefícios. Além disso, seria útil a analisar os impactos do consumo de energia e de renda sobre os aspectos menos tangíveis, tais como bem-estar, relacionar os preços dos combustíveis com a renda das famílias.

\section{Conflito de interesses}

Os autores declaram não haver conflito de interesses.

\section{Referências}

Arancibia, F. E. R. Consumo sustentável: padrões de consumo da nova classe média brasileira. Brasília: Universidade de Brasília, 2012. (Dissertação de mestrado).

Arthur, M. F. S. R.; Bucini, S. Z. G. On the adoption of electricity as a domestic source by Mozambican households. Energy Policy, v. 38, n. 11, p.7235-7249, 2010. https://doi.org/10.1016/j.enpol.2010.07.054

Arthur, M.; Bond, C. A.; Wilson, B. Estimation of elasticities for domestic energy demand in Mozambique. Energy Economics, v. 34, n. 2, p. 398-409, 2012. https://doi.org/10.1016/ j.eneco.2011.08.006

Atanassov, B.; Egas, A.; Falcão, M.; Fernandes, A.; Mahumane, G. Mozambique urban biomass energy analysis 2012: Maputo, Matola, Beira, Nampula. Maputo: Mozambique Ministry of Energy, 2012. Disponível em: <http://www.biofund.org.mz/wpcontent/uploads/2019/01/1548673665-Final Report Mozamique Urban Biomass 2012.pdf>. Acesso em: 23 abr. 2019.

Ateba, B. B.; Johannes, J.; Fourie, E. The impact of energy fuel choice determinants on sustainable energy consumption of selected South African households. Jounal of Energy in Southern Africa, v. 29, n. 3, p. 51-65, 2018. https://doi.org/10.17159/24133051/2018/v29i3a4714

Carvalho, A. A.; Alves, J. E. D. Padrões de consumo dos arranjos familiares e das pessoas que moram sozinhas no Brasil e em Minas Gerais: uma análise de gênero e renda. Anais do XIV Seminário sobre a Economia Mineira, Diamantina, 2010.

Carvalho, R. L. T.; Silva, Estudo compreensivo do conforto ambiental em habitações rurais do Ceará. Revista Geonorte, v. 2, n. 9, p. 1409-1421, 2012.

Coelho, S. T.; Sanches-Pereira, A.; Tudeschini, L. G.; Goldemberg, J. The energy transition history of fuelwood replacement for liquefied petroleum gas in Brazilian households from 1920 to 2016. Energy Policy, v. 123, p. 41-52, 2018. https://doi.org/10.1016/j.enpol. 2018.08.041

Cohen, C. A. M. J. Padrões de consumo: desenvolvimento, meio-ambiente e energia no Brasil. 2002. (Tese de doutorado).

Cohen, C.; Lenzen, M.; Schaeffer, R. Energy requirements of households in Brazil. Energy Policy, v. 33, n. 4, p. 555-562, 2005. https://doi.org/10.1016/j.enpol.2003.08.021

Crompton, P.; $\mathrm{Wu}, \mathrm{Y}$. Energy consumption in China: Past trends and future directions. Energy Economics, v. 27, n. 1, p. 195-208, 2005. https://doi.org/10.1016/j.eneco.2004. 10.006 
Deloitte. An overview of electricity consumption and pricing in South Africa: An analysis of the historical trends and policies, key issues and outlook in 2017. Johannesburg: Deloitte, 2017. (Report prepared for Eskom Holdings SOC Ltd). Disponível em: <http://www.eskom.co.za/Documents/EcoOverviewElectricitySA-2017.pdf>. Acesso em: 29 abr 2019.

Deus, S. A. J. Análise de consumo da madeira para fins de energia doméstica em três postos administrativos municipais da Cidade de Chimoio. Maputo: Universidade Eduardo Mondlane, 2014. (Projecto final de curso de graduação).

Dominik, E. C. Padrão de consumo familiar em diferentes estágios do ciclo de vida e níveis de renda - Bambuí-MG. Viçosa: Universidade Federal de Viçosa, 2010. (Dissertação de mestrado).

Dominik, E. C.; Silva, N. M.; Loreto, M. D. S.; Noronha, J. F. Padrão de consumo familiar em diferentes estágios de ciclo de vida e níveis de renda no Município de Bambuí-MG. Oikos: Família e Sociedade em Debate, v. 23, n. 1, p. 201-225, 2012.

Drukman, A.; Jackson, T. Household energy consumption in the UK: A highly geographically and socio-economically disaggregated model. Energy Policy, v. 36, n. 8, p. 3167-3182, 2008. https://doi.org/10.1016/j.enpol.2008.03.021

GASMIG - Companhia de Gás de Minas Gerais. Como converter a quantidade de um energético para a equivalente em gás natural. 2019. Disponível em: <http://www.gasmig.com.br/GasNatural/Paginas/Tabela-de-Conversao.aspx>. Acesso em: 23 abr. 2019.

Gil, A. C. Métodos e técnicas de pesquisa social. São Paulo: Atlas, 2008.

Hasan, S. A.; Mozumder, P. Income and energy use in Bangladesh: A household level analysis. Energy Economics, v. 65, p.115-126, 2017. https://doi.org/10.1016/j.eneco. 2017.05.006

Hosier, R. H.; Dowd, J. Household fuel choice in Zimbabwe. Resources and Energy, v. 9, n. 4, p. 347-361, 1987. https://doi.org/10.1016/0165-0572(87)90003-X

Howells, M. I.; Alfstad, T.; Victor, D. G.; Goldstein, G.; Remme, U. A model of household energy services in a low-income rural African village. Energy Policy, v. 33, p. 1833-1851, 2005. https://doi.org/10.1016/j.enpol.2004.02.019

IBGE - Instituto Brasileiro de Geografia e Estatística. Pesquisa de orçamentos familiares: POF 1995-1996, primeiros resultados. Rio de Janeiro: IBGE, 1997.

INE - Serviço Nacional de Estatística de Moçambique. Manual de consulta de dados. Sistema de Controlo Operativo de Censo de 2017. Maputo: INE, 2017.

IOF - Inquérito ao Orçamento Familiar. Relatório final do inquérito ao orçamento familiar - IOF-2014/15. Maputo: INE, 2015.

Jamasb, T.; Meier, H. Household energy expenditure and income groups: Evidence from Great Britain. Cambridge: Energy Policy Research Group, Cambridge Judge Business School, University of Cambridge, 2010. (Working Papers EPRG 1003). Disponível em: <https://ideas.repec.org/p/enp/wpaper/eprg1003.html>. Acesso em: 23 abr. 2019.

Kebede, B.; Bekele, A.; Kedir, E. Can the urban poor afford modern energy? The case of Ethiopia. Energy Policy, v. 30, n. 11/12, p. 1029-1045, 2002. https://doi.org/10.1016/ S0301-4215(02)00056-3

Keynes, J. M. A teoria geral do emprego: do Juro e da moeda. 1. ed. São Paulo: Atlas, 1992. 
Manuel, M. T.; Victorino, A. Padrões de consumo de energia no sector residencial: uma revisão bibliográfica. Revista Brasileira de Gestão Ambiental e Sustentabilidade, v. 7, n. 16, p. 605-618, 2020a. https://doi.org/10.21438/rbgas(2020)071610

Manuel, M. T.; Victorino, A. Padrões de consumo de energia no sector residencial: estudo de caso no 14을 Bairro Nhaconjo, Cidade da Beira, Moçambique. Revista Brasileira de Gestão Ambiental e Sustentabilidade, v. 7, n. 16, p.633-651, 2020b. https://doi.org/10.21438/rbgas(2020)071612

Moraes, A. M.; Martins, G.; Trigoso, F. M. 0 uso do fogão à lenha no semiárido piauiense: um estudo de caso. Anais do 7o Congresso Internacional sobre Geração Distribuída e Energia no Meio Rural, Fortaleza, 2008.

Neri, M. C. (Coord.). A nova classe média: o lado brilhante da base da pirâmide. São Paulo: Saraiva, 2011.

Rocha, C. B.; Dias, J. Padrão de consumo das famílias: uma análise do Município de Maringá. A Economia em Revista, v. 15, n. 1, p. 47-57, 2007.

SAE - Secretaria de Assuntos Estratégicos. Relatório de definição da classe média no Brasil. São Paulo: SAE, 2012.

Silva, C. C. População e consumo: efeitos de características sociodemográficas sobre o consumo de energia elétrica domiciliar em Lucas do Rio Verde (MT) e Santarém (PA). Brasil. Campinas: Universidade Estadual de Campinas, 2013. (Dissertação de mestrado).

Silva, F. M. B.; Ferreira, K. M. O.; Anésio, L. G. C.; Lopes, N. O.; Oliveira, T. T.; Dominik, E. C. Padrão de consumo das famílias urbanas de Bambuí-MG. Portal Jurídico: Investidura, 2018. Disponível em: <http://investidura.com.br/biblioteca-juridica/artigos/economia/ 336792-padrao-de-consumo-das-familias-urbanas-de-bambui-mg>. Acesso em: 23 abr. 2019.

Uchôa, C.; Pereira Junior, A.; Cohen, C.; Grottera, C.; Weiss, M.; Ferreira, D.; Menezes, N. Análise do padrão de consumo de energia por classe de renda nos domicílios Brasil. Anais do XVI Congresso Brasileiro de Energia, Rio de Janeiro, 2013.

Vale, A. T.; Resende, R.; Gonçalez, J. C.; Costa, A. F. Estimativa do consumo residencial de lenha em uma pequena comunidade rural do Município de São João D’Aliança, GO. Ciência Florestal, v. 13, n. 2, p. 159-165, 2003. https://doi.org/10.5902/198050981752

Weiss, M. Análise do consumo de energia direta e indireta das famílias brasileiras por faixa de renda. Rio de Janeiro: PPE/COPPE/UFRJ, 2015. (Dissertação de mestrado).

Yanagisawa, A. Impacts of income disparity on household energy consumption. Tokyo: IEEJ, 2012. Disponível em: <https://eneken.ieej.or.jp/data/4250.pdf>. Acesso em: 23 abr. 2019. 